\title{
Developing Retinotectal Projection in Larval Goldfish
}

\author{
CLAUDIA A.O. STUERMER AND PAMELA A. RAYMOND \\ Friedrich-Miescher-Laboratorium der Max-Planck-Gessellshaft, D-7400 Tuebingen, FRG \\ (C.A.O.S.), and Department of Anatomy and Cell Biology and Neuroscience Program, \\ University of Michigan, Ann Arbor, Michigan 48109-0616
}

\begin{abstract}
The retinotectal projection in larval goldfish was studied with the aid of anterograde filling of optic fibers with HRP applied to the retina. The results show that optic fibers have already reached the tectum and begun to form terminal arbors in newly hatched fish. The projection is topographic in that fibers from local regions of the retina project to discrete patches of tectum, with the smallest patch covering $3.5 \%$ of the total surface area of tectal neuropil. Many fibers in young larvae have numerous short side branches along their length and only some of them show evidence of terminal sprouting. The arbors are approximately elliptical in shape and average about $1,500 \mu \mathrm{m}^{2}$. Growth cones are seen frequently. In older larvae, terminal arbors are larger and more highly branched, and they have begun to resemble those in adult fish. Fibers terminate in two strata; those in the upper layer are smaller $\left(1,800 \mu \mathrm{m}^{2}\right.$ on average) than those in the deeper stratum $\left(4,000 \mu \mathrm{m}^{2}\right.$ on average). The fraction of tectal surface area covered by individual arbors (the "tectal coverage") ranges from $1.5 \%$ to $3 \%$ of the total surface area of the tectal neuropil. In contrast, the tectal coverage of individual arbors in young adult goldfish is much smaller, ranging from $0.02 \%$ to $0.42 \%$ of tectal surface area (Stuermer, '84, and unpublished). This apparent increase in precision of the map in older animals is not due to retraction of arbors, which are slightly larger in adults, but is accounted for by overall tectal growth: the tectal neuropil in goldfish increases in area by about 250 -fold during this period (Raymond, ' 86 ).
\end{abstract}

Key words: HRP filling, tectal wholemounts, axon terminals, axon ontgrowth, neuronal specificity

The regenerating optic nerve in adult goldfish has become a classic model system for studies of neuronal specificity. Optic fibers in teleost fish, as in amphibians, regenerate after they are severed, and they reestablish topographic connections with their target, the optic tectum (reviewed by Gaze, '70). Several studies in amphibians have described the development of retinotectal projections (cf, Gaze et al., '74). Recent experiments in Xenopus have shown that the initial pathway choices of growing optic axons in the developing embryo are remarkably precise (Sakagucki and Murphey, '85), and that fibers are organized along the dorsoventral axis, and perhaps also along the nasotemporal axis, from the time when they first appear in the tectum (Holt and Harris, '83; O'Rourke and Fraser, '86). The first report describing the early stages of development of retinotectal connections in fish (Stuermer, '88c) is consistent with the results in amphibians.
In goldfish, formation of the retinotectal projection has not previously been studied at the earliest stages of development, but only in growing juveniles and adults. Both retina (Johns and Faster, '77; Meyer, '78) and optic tectum (Raymond and Easter, '83) in goldfish continue to grow by adding new neurons. The rate of addition of new ganglion cells, and hence new optic fibers, is about 50 per day in young adults (Easter et al., ' 81 ). The germinative neuroepithelium in the retina lies at the peripheral margin, where it generates annuli of new retinal cells (Johns and Easter, '77). The tectal germinal zone also lies at the boundary of the differentiated tissue, but in this case the neuroepithelial cells form

Accepted October 14, 1988.

Address reprint requests to Dr. Pamela A. Raymond, Department of Anatomy and Cell Biology, The University of Michigan Medical School, 4610 Medical Sciences II, Ann Arbor, MI 48109-0616. 
only a partial annulus, with the open end pointed rostrally (Raymond and Easter, '83; Raymond, '86). The gap in the germinal zone is coincident with the region where the optic tract enters the tectum. As a result of this topographic mismatch in the patterns of retinal and tectal growth, the retinotectal projection is in constant flux (Easter and Stuermer, '84; Stuermer and Easter, '84b; Raymond, '86). Optic fibers continually shift caudally, on the one hand to colonize newly added tectal territory, and on the other hand to make room at the rostral end for newly arriving fibers whose topographic "address" dictates they belong there, despite the lack of new tectal neurons in that region. A similar phenomenon occurs during larval development in amphibians, where it was first predicted by Gaze and colleagues (Gaze et al., '74) and subsequently documented experimentally (Fraser, '83; Reh and Constantine-Paton, '84; Hitchcock and Easter, '87). Nothing is known about how the terminal arbors of optic fibers actually shift across the tectum during growth, except that the moving terminals leave a permanent trace of where they traveled as the axons elongate. Hence optic fibers within the tectum have very complex but highly predictable trajectories (Easter and Stuermer, '84; Stuermer and Easter, '84b).

In contrast to amphibians, little is known about the earliest stages in the development of the retinotectal projection in fish (Stuermer, '88c). There have been some reports describing the morphological development of the teleost retina (Müller, '52; Hollyfield, '72; Johns, '82) and optic tectum (Rahmann and Jeserich, '78; Raymond, '86), but these have not dealt with the outgrowth of fibers along the optic pathway and their termination in the tectum. The latter is the subject of this study.

We have used anterograde filling of ganglion cell axons with horseradish peroxidase (HRP) applied to a retinal lesion to examine the pathways and axonal arborizations of optic fibers within the tectum of larval goldfish. Our results show that: (1) optic fibers had already reached the tectum by the first day after hatching (the earliest time we examined), (2) the fibers in young larvae (1-2 days after hatching) had abundant short side branches along their length but little terminal branching, whereas in older larvae (14 days) terminal arbors were more highly developed, and side branches proximal to the arbor were less frequent, (3) terminal arbors in larval fish covered only about one-eighth the area of those in adults, but the fraction of tectal surface covered by an individual arbor in the larvae was greater (up to 100 -fold more) than in adults, and (4) some indication of retinotopic order was evident even in early larvae. A preliminary report of these results has been published in abstract form (Raymond and Stuermer, '87).

\section{MATERIALS AND METHODS}

Goldfish embryos were obtained from spawnings induced in the laboratory with techniques described previously (Raymond, '85). The breeding stock came from Ozark Fisheries (Richland, MO). Embryonic and larval goldfish were reared at $21^{\circ} \mathrm{C}$ as described previously (Johns, ' 82 ). At this temperature, the embryos hatch approximately 100 hours after fertilization, and larval development lasts approximately 3 weeks, ending when differentiation of the fin rays is completed (Kajishima, '60). Here, we refer to larvae by age (e.g., 1 day, 2 days, etc.), which we define as days after hatching, with the day of hatching designated as day 0 .

To label optic fibers, crystals of horseradish peroxidase (HRP, Bayer-Miles Ltd.) were taken up on the tip of a glass micropipet (approximate tip diameter, $50 \mu \mathrm{m}$ ). Larvae $(1,2$, or 14 days after hatching) were anesthetized with tricaine methanesulfonate $(0.01 \%)$ and held between layers of wet tissue. A small hole was made in the cornea with a sharpened metal needle, and the pipet carrying the crystal of HRP was inserted into the retina and allowed to dissolve. The size of the crystal and its placement in the retina were intentionally varied in order to label variable numbers of ganglion cell fibers of differing topographic positions. After survival times of 15 minutes or 3 to 4 hours, whole fish were fixed for 15 minutes in $4 \%$ glutaraldehyde in $0.1 \mathrm{M}$ phosphate buffer, $\mathrm{pH}$ 7.4. They were then rinsed in buffer, the skin overlying the brain was gently peeled off, and the heads were removed and processed for HRP histochemistry with 3,3-diaminobenzidine (Sigma) as the chromogen $(1 \mathrm{mg} / \mathrm{ml}$ in phosphate buffer with 1 drop of $30 \%$ hydrogen peroxide in $20 \mathrm{ml}$ ). The reaction was allowed to proceed in the dark at room temperature for 30 minutes, with constant agitation. The heads were rinsed in buffer and then placed back into $4 \%$ glutaraldehyde to continue the fixation overnight at $4^{\circ} \mathrm{C}$. The following day the heads were rinsed in buffer and the brains were dissected out and in most cases (48 of 62) were mounted whole (dorsal side up) by pressing them onto gelatin-subbed slides under a 5-10 g weight for 3 hours. The whole mounts were dehydrated in ethanol, cleared in $x y-$ lenes, and coverslipped in D.P.X. (BDH Chemicals Ltd.). A few brains (7 of 62) were dehydrated, cleared in methylsalicylate, and examined as free-floating specimens. This was done as a control to gauge the amount of distortion produced by the wholemount procedure. Finally, with the remaining 7 (of 62) preparations, the brains were not dissected out; instead the whole head was dehydrated and embedded in glycomethacrylate resin (JB-4, Bio-Rad Laboratories, NY) and sectioned at $3 \mu \mathrm{m}$.

Labeled axons were viewed and photographed with a Zeiss Axiophot equipped with Nomarski optics. Camera lucida drawings were made with $100 \mathrm{x}$ oil immersion objectives and Nomarski optics. Thirty-six of the 48 wholemount preparations had labeled axons that were suitable for drawing. Terminal arbors were drawn and their sizes estimated as follows. A boundary was drawn enclosing the tips of all processes, and the long and short axes of the resulting elliptically shaped polygons were measured. The area covered by the arbor was estimated by using the formula for the area of an ellipse. Similarly, the surface area of tectal neuropil was estimated from mediolateral and rostrocaudal dimensions measured on the wholemounts.

\section{RESULTS \\ Retinotectal projections in young larval goldfish}

A previous description of the cytoarchitecture of the optic tectum in larval goldfish (Raymond, '86) indicates that at the larval stages investigated in the present study, the optic tectum has a central differentiated core that consists of a deep cellular layer and an overlying neuropil. Surrounding the differentiated center is a wide rim of mitotically active neuroepithelium. At this stage, the germinal rim is up to 100 $\mu \mathrm{m}$ wide, and the overall length/width of the tectum is no more than $300 \mu \mathrm{m}$. The tectal surface is quite flat and only gradually (over the next several weeks) attains the marked curvature characteristic of the adult tectum (Raymond and Easter, '83; Raymond, '86). These earlier results were based on serial reconstructions of sectioned material that was processed for thymidine autoradiography to reveal the loca- 

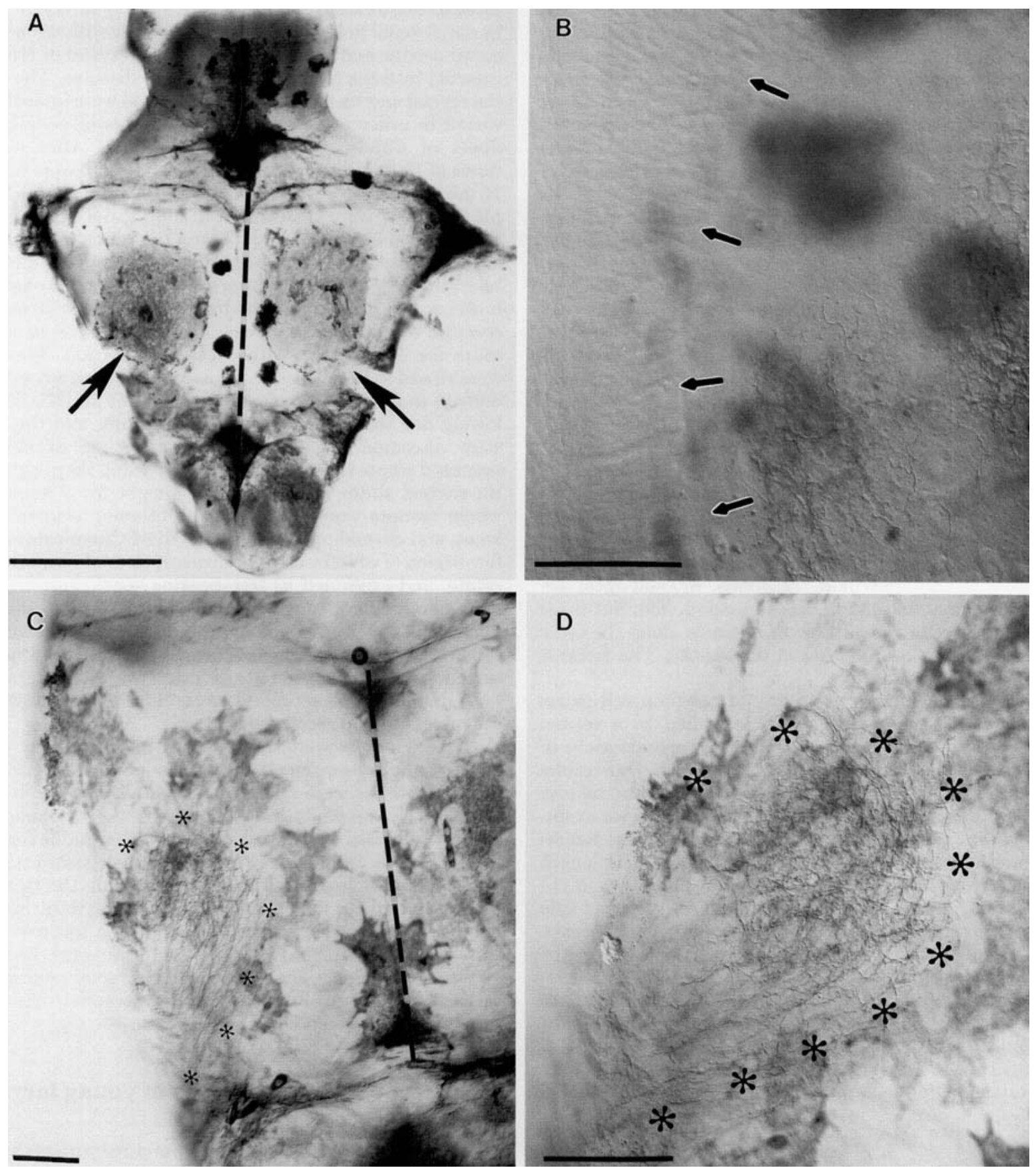

Fig. 1. The optic tectum in larval goldfish. A. This is a wholemounted preparation of a newly hatched larval goldfish brain. The tectal lobes are the paired, egg-shaped structures indicated by the arrows, and the midline is shown by the dashed line. Rostral is down in this and all subsequent figures. The tectal neuropil is the central, circular, dark core, and it is surrounded by an unstained rim of proliferating neuroepithelium. The right tectum of this fish (left side in the figure) contained HRP-labeled fibers in the central core; in the left tectum there were no

labeled fibers, but the central core is slightly darkened because of background staining. B. The neuroepithelial cells in the rim (arrows) at higher magnification in a different preparation. This tectum is from a 2-week-old larva, which was cleared in methyl salicylate and examined free-floating. C. In this wholemounted preparation from a 2-day-old fish, HRP-labeled fibers penetrate the neuropil region of the right tectal lobe, which is outlined by asterisks. D. A higher magnification of the labeled fibers shown in C. Calibration bars: A $250 \mu \mathrm{m} ; \mathrm{B}, \mathrm{C}, \mathrm{D}, 50 \mu \mathrm{m}$. 
8
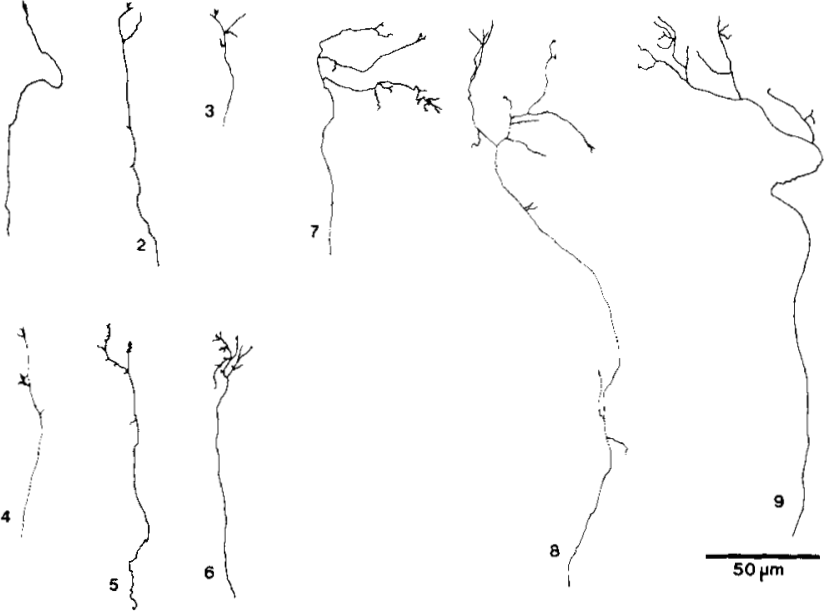

Fig. 2. Terminal arbors in young larval tecta. These are camera lucida drawings of representative terminal arbors, ranging from simple ( $\# 1$ ) to complex (\#9). Notice the short side branches on the axon shaft proximal to the terminal arbor on fibers $\# 2,4,5$, and 8 .

tions of the dividing cells in the germinal zone. The germinal zone is at the perimeter of the tectal disc, but it does not form a complete annulus; there is a gap at the rostrolateral edge (Raymond and Easter, '83; Raymond, '86).

These morphological features were also seen in the wholemount preparations of the present study (Fig. 1A). The central core of neuropil in the HRP preparations typically showed some background staining and was easily distinguished from the unstained rim of neuroepithelium. In most preparations the elongated, densely packed cells in the neuroepithelium could be visualized with Nomarski optics, as shown in Figure 1B. Labeled optic fibers were confined to the central neuropil core (Fig. IC, D), and only occasionally did a fiber stray into the cellular neuroepithelium at the caudal end, and even then only for a short distance (no more than about $50 \mu \mathrm{m}$ ) (Fig. 1D).

The optic fibers in young larvae (1- to 2-days old) ranged from simple, unbranched axons tipped by a growth cone (\#1 in Fig. 2) to those with branched terminal arbors (\#6-9 in Fig. 2). Many of the fibers at this stage were characterized by short side branches scattered along the proximal shaft at some distance from the terminal arbor ( $\# 2,4,5,8$ in Fig. 2). Most branches ended in growth cones (Fig. 3). The best preparations at this age were from the group with a transport time of 15 minutes. In animals processed 3 or 4 hours after application of HRP, many of the labeled fibers showed signs of degeneration, and growth cones were absent (not illustrated). The distance from ganglion cell soma to axon terminal is approximately $250 \mu \mathrm{m}$ at this stage.

Figure 4 illustrates the overall pattern of labeled axons and terminal arbors in the optic tecta of young larvae. The outer boundary of the tectal rim was drawn and, in those preparations in which it was visible, the boundary of the central core of neuropil was also traced. Although these drawings do not necessarily include all of the labeled optic fibers, there were none outside the regions in which labeled fibers are shown. It was difficult to place the HRP accurately in these eyes since they were so small, but we did attempt to systematically vary both the size and the placement of the retinal lesion. Correspondingly, we found that the terminal fields of labeled fibers varied in size and location in the tectal wholemounts. For example, in Figure 4B most of the labeled fibers traveled in a loose bundle along the lateral border of the neuropil region and began to arborize in a restricted location about midway along the rostrocaudal dimension. In the preparation in Figure $4 \mathrm{~A}$, the labeled fibers again entered laterally, but in this case they arborized in a more rostral region. In Figure $4 \mathrm{C}, \mathrm{D}$, the fibers arborized in the central region of the neuropil, and in Figure $4 \mathrm{E}, \mathrm{F}$, the caudal half contained most of the labeled terminal arbors.

These observations suggest that optic axons in the early larvae may be ordered retinotopically in the tectum. In most preparations we could identify a patch of tectal neuropil, variable in size and location, in which the vast majority of labeled terminal arbors were located; in a few preparations the entire tectal neuropil contained labeled terminal arbors. As stated above, this is consistent with the variable size and placement of HRP in the retina. We cannot make a definitive statement about the retinotoptic order of the projection, because the eyes were usually damaged during dissection of the brain, and so we could not verify the retinal location of the labeled somas. We had hoped that we would be able to identify the injection site in the retina in the methacrylate sections of whole heads, but unfortunately in these preparations the histochemical reaction did not work in the retina, presumably because the substrate failed to penetrate the eye. Nevertheless, the fact that labeled fibers tended to arborize in discrete zones or patches suggests that fibers originating from neighboring retinal ganglion cells sought out a common target region, and that in itself indicates a certain degree of retinotopy.

The pathways taken by labeled fibers on the way to their destinations were not always straight and orderly. Many examples of fibers with bends and hairpin turns were seen (e.g., \#1 and \#9 in Fig. 2, and Fig. 4F). These profiles resemble descriptions of regenerating optic fibers in adult goldfish (Stuermer and Easter, '84a; Schmidt et al, '88; Stuermer, ' $88 \mathrm{a}, \mathrm{b})$. The loops and bends are thought to represent course corrections made by fibers searching for their appropriate targets. In contrast, optic fibers in intact adult goldfish are typically more orderly (Stuermer, '84; Stuermer and Easter, '84a,b).

\section{Retinotectal projections in older larval goldfish}

The optic tecta in 2-week-old larvae were similar to younger larvae, although larger (see below). In these older fish, a 3-to 4-hour survival time following application of HRP resulted in good labeling of fibers, including growth cones, with no evidence of the degeneration that was seen with these survival times in younger larvae. Optic fibers were restricted to the central core, or neuropil region. For example, in the tectum illustrated in Figure 5A, all or most of the retinal fibers appeared to be labeled, and the entire neuropil was stained. However, as in younger larvae, the labeled terminal arbors often did not cover the entire neuropil. In some of these older animals the patches of labeled terminal arbors were even more discretely localized than in younger larvae, and again the patches varied in tectal location. For example, in Figure 5B, the labeled patch was in caudomedial tectum, whereas in Figure 5C the label was confined to a zone in lateral tectum, about midway along the rostrocaudal dimension. In a few preparations we observed multiple patches of label, such as in the tectum illustrated in 

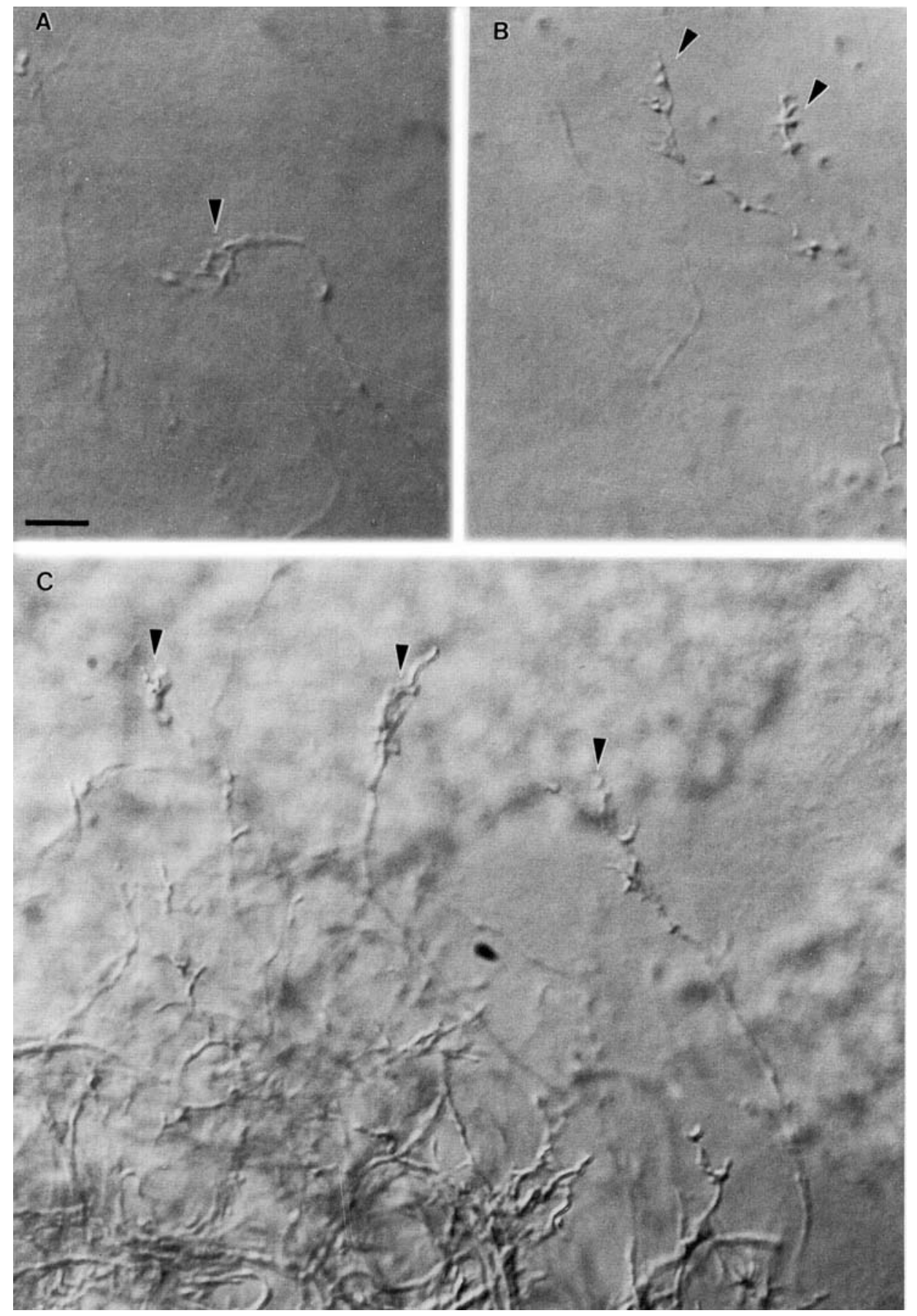

Fig. 3. Examples of growth cones (arrows) in young larval tecta. Calibration bar: $5 \mu \mathrm{m}$.

Figure 5D. The pattern of labeled fibers in this tectum was similar to what one would see following labeling of the peripheral nasal retina in adult goldfish. In adults, fibers from dorsal retina enter through the lateral brachium and those from ventral retina enter through the medial brachium (Bernhardt and Easter, '86). The labeled fibers in Figure 5D similarly entered the tectum in two discrete brachia, one lateral, the other media, and they arborized on the lateral and medial sides of the tectum, respectively.
The relative size of these labeled patches gives some indication of the degree of precision of the retinotectal map. The labeled patches in Figure 5B, C covered $14 \%$ and $19 \%$, respectively, of the total area of available tectal neuropil. The smallest patch was in another preparation (not illustrated), and it covered only $3.5 \%$ of the tectal neuropil.

Terminal arbors of labeled fibers in these older larvae were more elaborate than those at earlier stages (Figs. 6A, 7). The overall shape of some of them (e.g., \#4 and \#5 in Fig. 


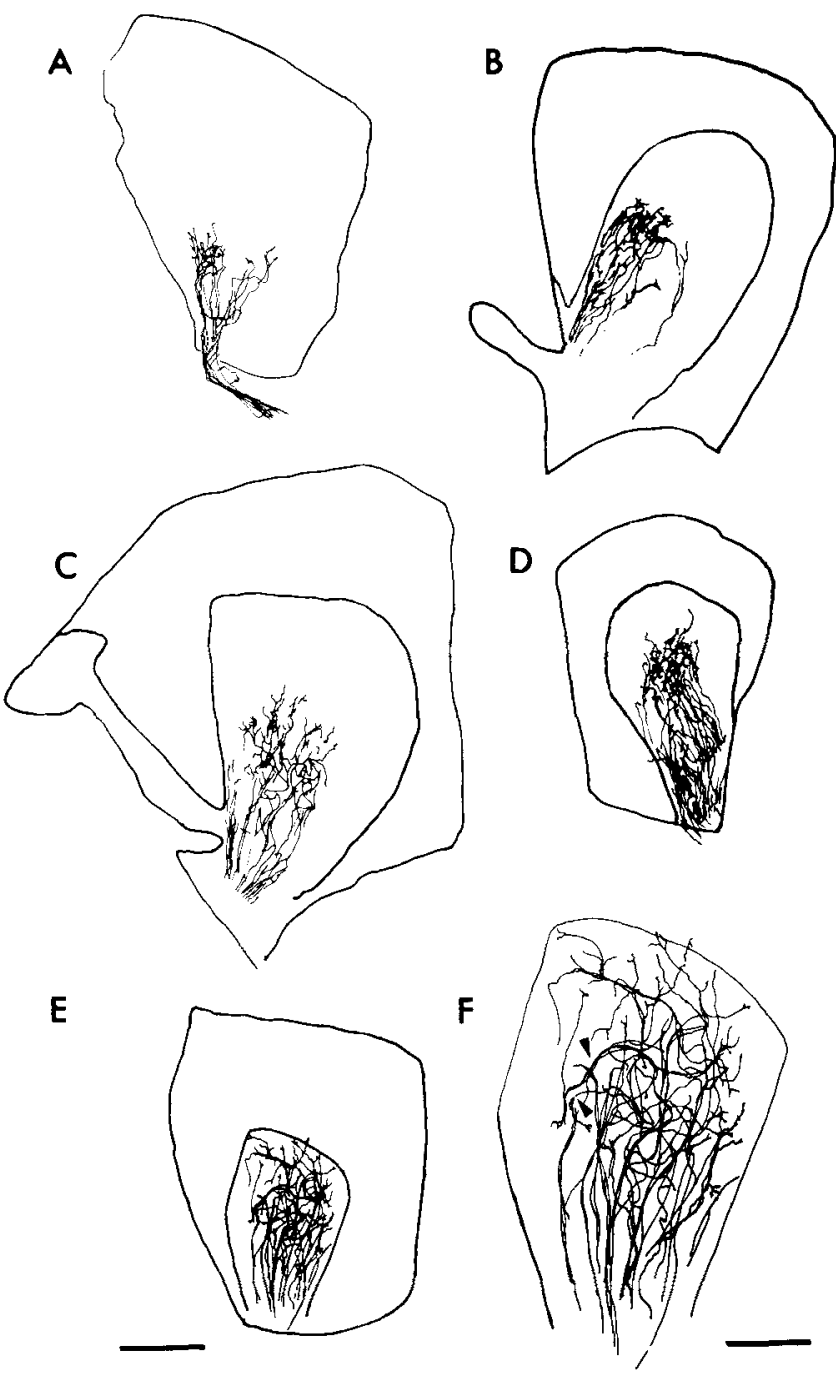

Fig. 4. Pattern of labeled fibers and terminal arbors in young larvae. These are camera lucida drawings of tecta with labeled fibers. Rostral is down in all panels, and medial is to the right in $A, B, C, E$ and $F$, and to the left in D. In panels $B-\mathbf{E}$ the outermost line denotes the edge of the tectum, and the inner $U$-shaped line indicates the boundary between the core neuropil and the germinal rim. In the preparation illustrated in panel $\mathbf{A}$, the boundary between core and rim could not be distinguished. Panel $F$ shows, at a higher magnification, the neuropil boundary and labeled fibers from panel $E$. The arrowheads in $\mathrm{F}$ indicate fibers with complex trajectories. Calibration bars: $\mathrm{E}$, $100 \mu \mathrm{m}$, also applies to A through $\mathrm{D} ; \mathrm{F}, 50 \mu \mathrm{m}$.

7) had begun to resemble the terminal arbors in adult goldfish tectum (Stuermer, '84), with a Y-shaped primary bifurcation and elongated arms that ended with profuse branching. Most of the short side arms that had been on the proximal shaft in young larvae had disappeared by this stage (compare Figs. 2 and 7), but many branches still had growth cones at their tips (Fig. 6).

In the older (but not the younger) larvae, two strata of terminal arbors could be distinguished when focusing down through the tectal layers. The dimensions of the arbors were different in the two layers; the largest arbors were typically in the deeper stratum. This stratification of terminals by size probably represents an early phase in the development of sublaminae F2/F3 and F4, which are subdivisions of the principal synaptic layer for optic afferents in the tecta of adult goldfish (Stuermer, '84). In adults, the deeper laminae F4 is distinct from the more superficial F2/F3 in that the former contains predominately large arbors, whereas the latter includes small and medium-size arbors with only an occasional large one.

\section{Size of the terminal arbors of optic fibers in larval goldfish}

The terminal arbors of optic fibers in larval goldfish grew rapidly during the first 2 weeks. We measured the dimensions of 63 terminal arbors that were sufficiently well isolated and stained that they could be drawn completely (see Methods). The lengths of the short and long axes of each arbor are plotted on Figure 8A. The short side branches on fibers in young larval tecta (Fig. 2) were not considered part of the terminal arbor; for purposes of measurement, lateral branches more than about $35 \mu \mathrm{m}$ proximal to the primary bifurcation were excluded. In general, the long axis of the arbor was aligned with the rostrocaudal tectal axis. Arbors in 14-day-old fish were, on average, somewhat larger than those at 1 and 2 days, and at 14 days those in the deeper layer were larger than those located more superficially (Fig. $8 \mathrm{~A})$. The tectum also enlarged, and the neuropil region, measured on the wholemounts, more than doubled in both mediolateral and rostrocaudal extent during this 2-week interval (Fig. 8B). In length, the largest arbors extended to $30 \%$ of the entire rostrocaudal dimension of the neuropil, and in width, the largest ones were about $25 \%$ of the mediolateral dimension. This is a very different situation from that in adult goldfish, where the tectum is several millimeters long (Raymond and Easter, '83; Raymond, '86), but terminal arbors are, on average, $100 \mu \mathrm{m} \times 160 \mu \mathrm{m}$ (Stuermer, '84), i.e., not much larger than the largest terminals in the 14-day-old larvae.

The area covered by each individual terminal arbor, expressed with reference to a planar projection of the tectal neuropil, was calculated from the lengths of its long and short axes, using the formula for an ellipse. These values are plotted in Figure 9A as a function of age. The terminal arbors in 1- and 2-day-old larvae were similar in size; the combined mean was $1,480 \mu^{2}$ (standard deviation, 1,101 $\mu \mathrm{m}^{2}$ ). In older larvae, terminal arbors in the upper stratum had increased slightly in size (mean, $1,806 \mu \mathrm{m}^{2}$; standard deviation, $387 \mu \mathrm{m}^{2}$ ), whereas those in the deeper layer were more variable, ranging from $1,000 \mu \mathrm{m}^{2}$ to almost $10,000 \mu \mathrm{m}^{2}$, with a mean of $4,102 \mu \mathrm{m}^{2}$ (standard deviation, $2,279 \mu \mathrm{m}^{2}$ ). The size of terminal arbors was also computed as a percentage of total tectal neuropil surface area, and these values (defined as the "tectal coverage") are given in Figure 9B. The percentage of tectal neuropil area covered by an individual terminal arbor was about $2 \%$ in both 1 - and 2-dayold fish. In 14-day-old fish the larger arbors in the deeper stratum averaged about $3 \%$ of the tectal area, and the smaller ones in the upper layer were about $1.5 \%$. For comparison, terminal arbors in adult goldfish tecta range each covered only $0.02 \%$ to $0.42 \%$ of total tectal area (Stuermer, '84 and unpublished).

\section{DISCUSSION}

The results of this study have shown that retinal fibers innervate the tectum in larval goldfish. In young larvae (1 to 2 days after hatching), many axons are immature in appearance and lack a terminal arbor. These immature fibers have growth cones on their leading process and often have short side branches distributed along their length. Their appear- 

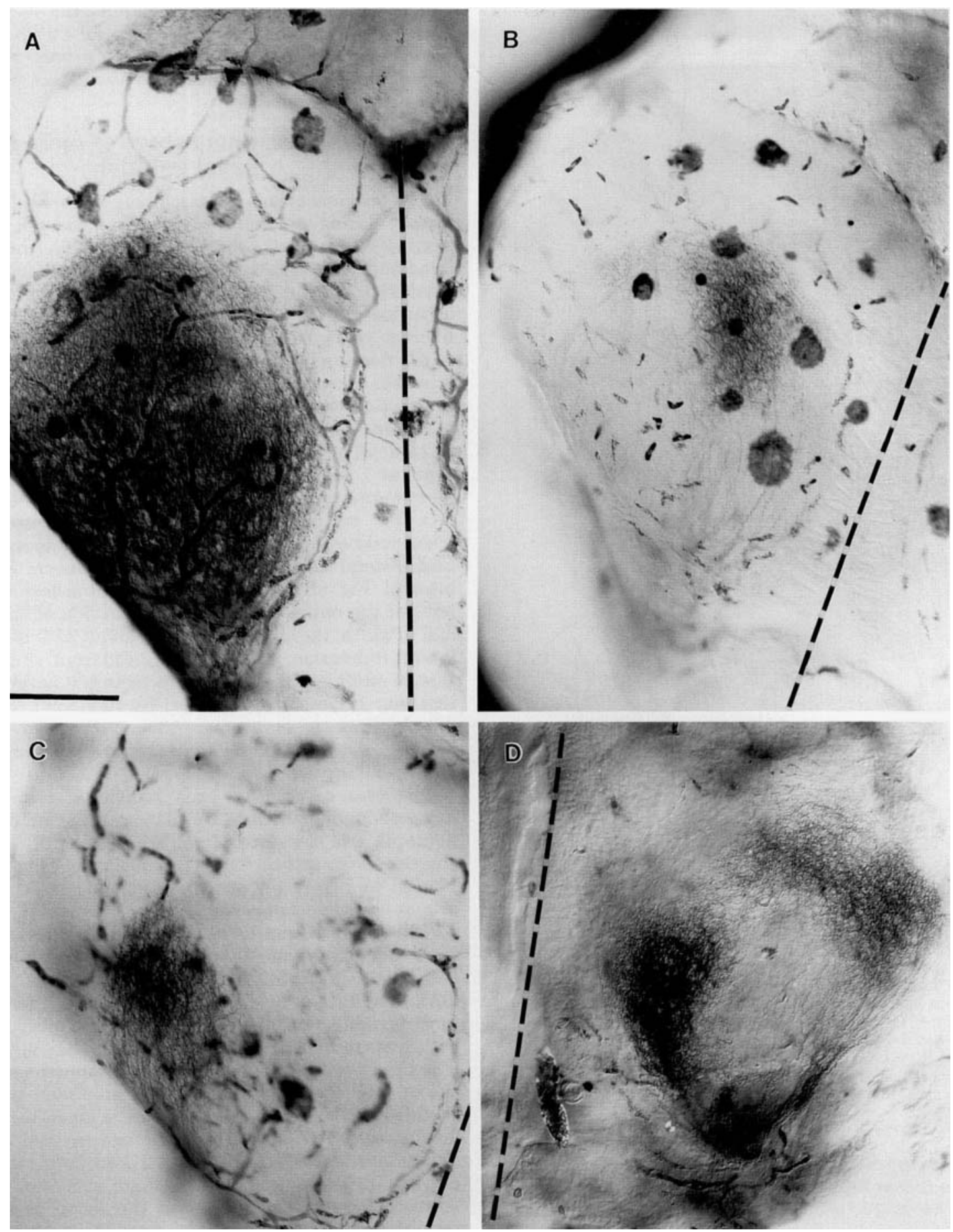

Fig. 5. Pattern of labeled fibers and terminal arbors in older larvae. These are photomicrographs of wholemounted tecta. The midline in each is indicated by a dashed line. A. Fibers throughout the tectal neuropil are labeled. In the other panels, the labeled fibers arborize in restricted zones (see text). Calibration bar: A, $100 \mu \mathrm{m}$, applies to all panels.

ance is similar to descriptions of optic afferents as they first grow into the dorsal lateral geniculate nucleus in fetal kittens (Sretavan and Shatz, '86). The short side branches are thought to represent a kind of searching mode, since they are characteristic of growing fibers that are seeking but have not yet reached their terminal destination. In kittens, the side branches are eliminated at later stages of development, when the terminal arbor begins to sprout (Sretavan and Shatz, '86). Likewise in older (2 week) larval goldfish, we found that many of the fibers have begun to elaborate a terminal arbor, and there are fewer proximal branches.

We found suggestive evidence that retinal fibers in larval goldfish are topographically ordered: local applications of HRP to various sites in the retina give rise to discrete bun- 

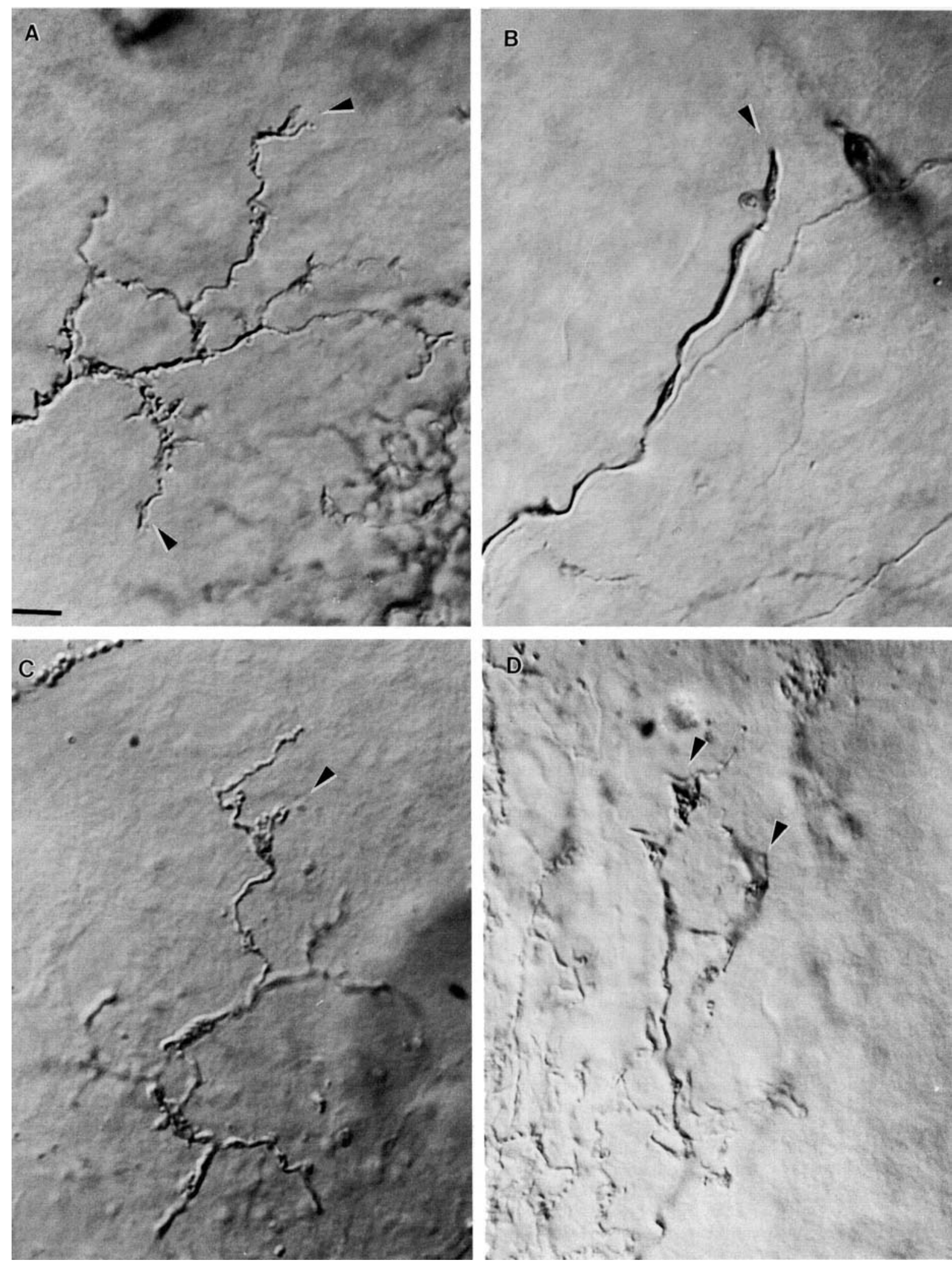

Fig. 6. Examples of terminal arbors and growth cones (arrowheads) in older larvae. Calibration bar: $5 \mu \mathrm{m}$, applies to all panels. 

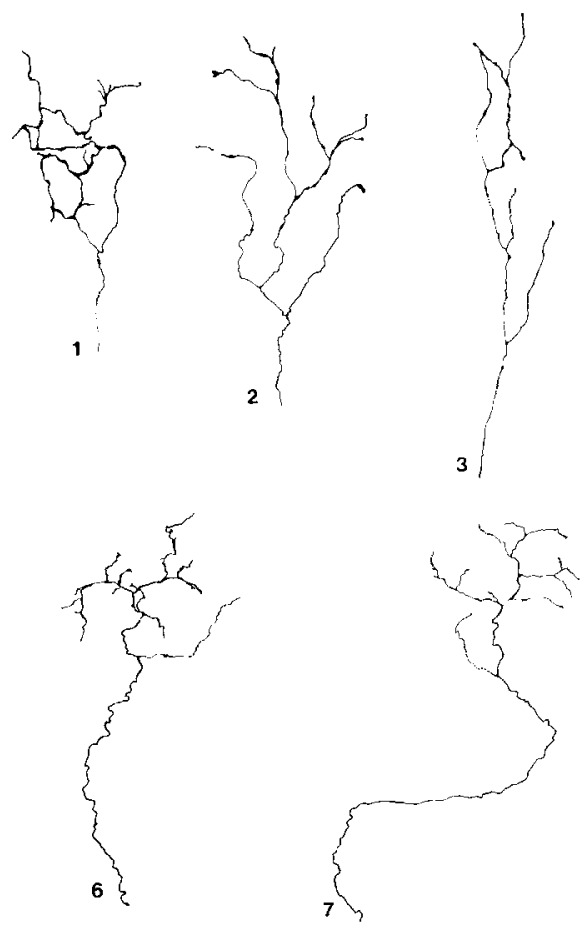
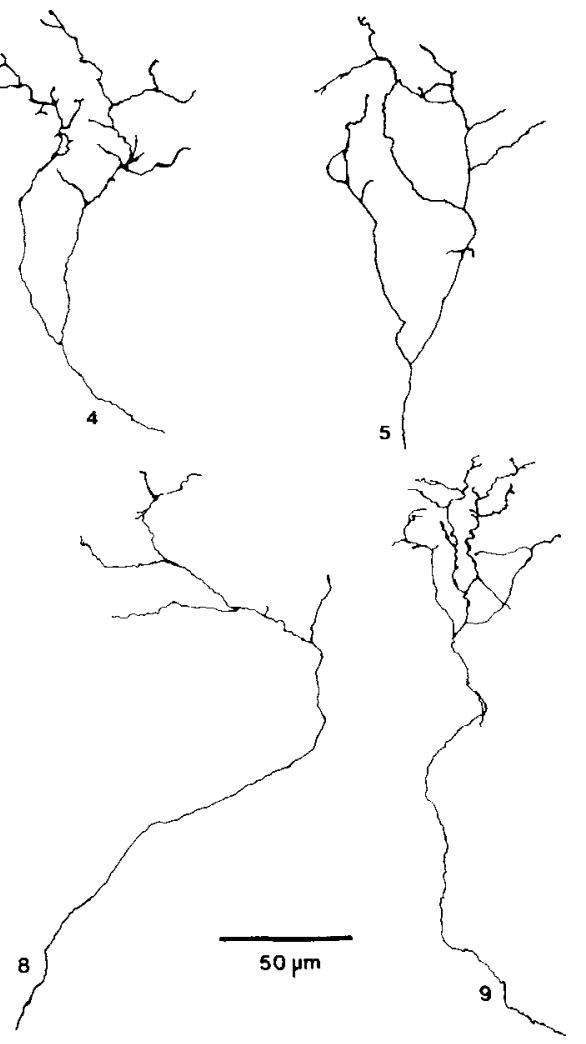

Fig. 7. Terminal arbors in older larvae. These are camera lucida drawings of representative terminal arbors.

dles of labeled fibers that ramify within restricted zones in the tectal neuropil. These patches containing labeled terminal arbors are of variable size, in accord with our deliberate attempt to vary the number of labeled retinal fibers by varying the quantity of HRP applied. The location of the labeled patches on the tectum also varied, again as expected, since we placed the HRP in different retinal locations. We could not confirm the site of HRP application in the retina, so we cannot comment on the whether the projection is retinotopically ordered.

Recently, Stuermer ('88c) described the development of the retinotectal projection in zebrafish embryos. In that study ganglion cell axons were labeled by anterograde filling with either HRP, as in the present study, or with the fluorescent carbocyanine dyes, dil and diO. The first axons to emerge from the embryonic eye were labeled, and the subsequent pattern of tectal innervation was described. The results showed that the retinotectal projection in these embryonic fish is retinotopically organized from the earliest stages. By labeling one-half of the retina with diI, which fluoresces red, and the opposite half of the retina with diO, which fluoresces green, Stuermer showed that the earliest axons dorsal and ventral retina segregate at the brachium of the tract and arborize in the appropriate half of the embryonic tectum. Axons from nasal and temporal retina enter the rostral tectum together, but those from nasal retina continue growing into caudal tectum, whereas temporal fibers stop and terminate rostrally. The results of the present study, which began with a later stage in development, are consistent with the conclusion that the developing retinotectal projection in fish is retinotopically organized.

The terminal arbors of optic fibers in zebrafish embryos (Stuermer, '88c) are similar in appearance but smaller than those in goldfish larvae $(50 \mu \mathrm{m} \times 70 \mu \mathrm{m}$ versus $100 \mu \mathrm{m} \times 150$ $\mu \mathrm{m}$, maximum dimensions). Terminal arbors in adult zebrafish (Stuermer, '88c) are about the same size as those in adult goldfish (Stuermer, '84), ranging up to about $150 \mu \mathrm{rn} \times$ $200 \mu \mathrm{m}$. This equivalence in size of optic terminals is interesting since adult zebrafish are much smaller than the adult goldfish used in these studies $(2 \mathrm{~cm}$ to $3 \mathrm{~cm}$ versus $5 \mathrm{~cm}$ to 8 $\mathrm{cm}$ in body length, respectively).

Sakaguchi and Murphey ('85) have suggested that the retinotopic map in embryonic Xenopus is less precise than in adult animals in that individual arbors typically cover a large fraction of the tectal neuropil, up to $75 \%$ of tectal length and $35 \%$ of its width, even though the overall size of individual arbors is less than in adults (Sakaguchi and Murphey, '85). In zebrafish embryos, the largest arbors are $40 \%$ and $20 \%$ of the tectal length and width, respectively (Stuermer, ' $88 \mathrm{c}$ ), and the values we found in goldfish larvae are similar, $30 \%$ and $25 \%$, respectively. Another way to evaluate the size of terminal arbors and to estimate the precision of the map is to calculate the relative surface area covered by individual arbors. We call this measure the "tectal coverage." The tectal coverage of individual arbors is 7 -fold higher in larval zebrafish compared to adults (Stuermer, '88c) and 100-fold higher in larval compared to adult goldfish (present results). This decrease in the relative (but not the absolute) size of terminal arbors is due to continued growth of the tectum accompanied by addition of new retinal afferents and new tectal neurons. The result is a gradual increase in the relative precision of the retinotopic map, but not because the arbors shrink. The arbors increase somewhat in size as they mature, but the tectum expands enormously. The change is greater in goldfish than in zebrafish because goldfish grow to be larger. Postembryonic tectal 

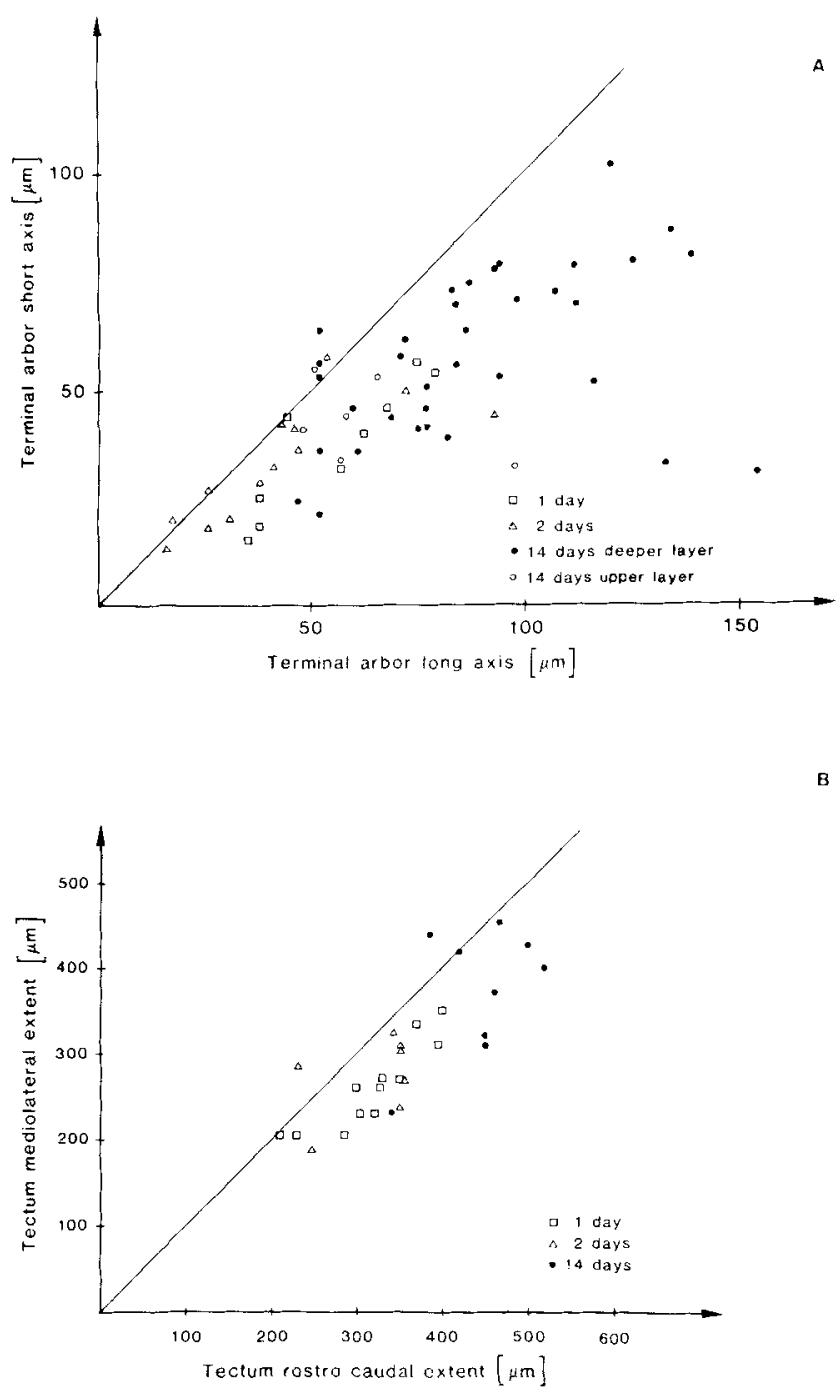

Fig. 8. Dimensions of terminal arbors and optic tecta. A. Terminal arbors were measured as described in Methods. The line has a slope of 1 , and the amount that the points deviate from the line is a measure of the elliptical shape of the arbors. B. Dimensions of the neuropil region are plotted. The tectal neuropil is nearly circular in shape.

growth also accounts for the apparent increase in precision of the retinotectal map during development in larval Xenopus (Sakaguchi and Murphey, '85).

The pathways taken by growing optic fibers in goldfish larvae are generally target-directed, with only occasional examples of major changes in direction. Optic fibers in embryonic zebrafish behave similarly (Stuermer, '88c). Misrouted fibers have also been described during the early phases of optic nerve regeneration in adult goldfish, but under those conditions many more fibers have abnormal trajectories and one gets the overall impression of decreased precision compared to intact adults (Fujisawa, '81; Stuermer and Easter, '84a; Taylor and Gaze, '85; Becker and Cook, '87).

The evidence summarized above is consistent with the hypothesis that when optic fibers in fish and amphibians first grow out to innervate the tectum during development, they do so in an orderly and directed fashion, following cues
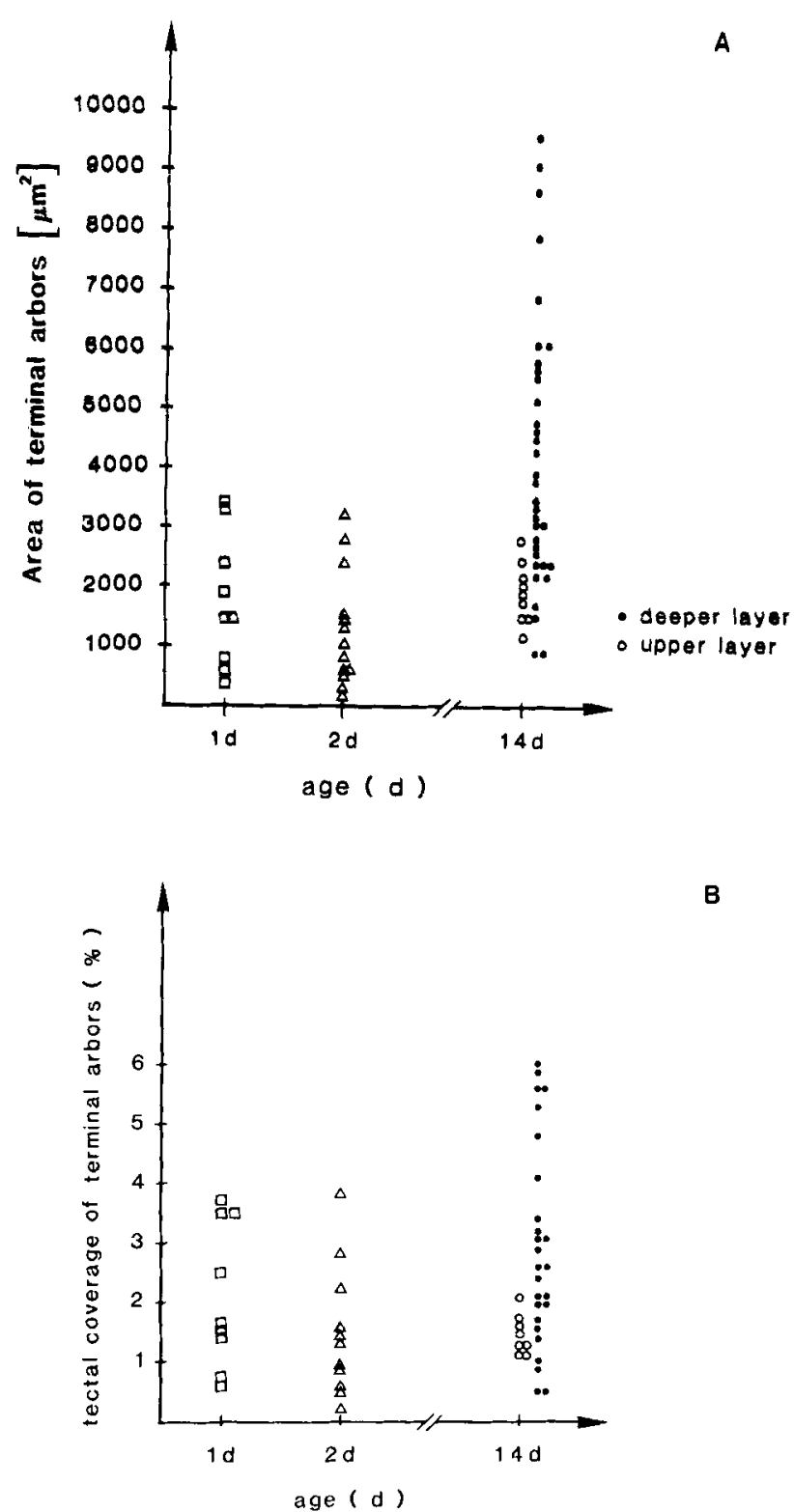

Fig. 9. Area of terminal arbors. A. Area of terminal arbors calculated as described in the Methods and plotted as a function of age in days. See Results for further explanation. B. 'Tectal coverage is defined as the area of each arbor expressed as a percentage of total surface area of the tectal neuropil, and it is plotted as a function of age in days. See Results for further discussion.

that lead them almost unerringly to their target. A number of different mechanisms have been proposed as potential guidance factors, including interactions with other fibers of similar retinotopic address, interactions with glial cells along the pathway, and chemical cues in the tectum that provide information about direction or polarity (reviewed by Gaze, '70; Easter, '86; Fujisawa, '87). A novel mechanism recently proposed by Bonhoeffer and colleagues (Walter et al., ' $87 \mathrm{a}, \mathrm{b}$ ) is that an inhibitory factor produced by (caudal) tectal cells impedes the outgrowth of certain (temporal) retinal fibers. The factors involved in axonal guidance during regeneration are probably similar to those active during development, but it is becoming increasingly clear that the mechanisms may not be identical. The most convincing evi- 
dence in support of this notion is that the pathways taken by regenerating fibers and the initial map they form is more diffuse than in adults or even in developing embryos. Over time, the precision of the regenerated retinotectal map gradually improves, and this improvement is thought to be driven by a mechanism dependent on neural activity, since it is blocked by the application of tetrodotoxin (TTX) (reviewed by Schmidt, '85). Neural activity seems not to be important for the initial formation of the map, since TTX applied during development does not prevent the establishment of a retinotopically ordered projection (Harris, ' 80 , '84). Neural activity is thought to be involved in later refinements that are accomplished by elimination of inappropriate axonal branches (Schmidt, '85).

In summary, this study examined for the first time the retinotectal projection in larval goldfish. By labeling a portion of the total population of retinal fibers with HRP, we found evidence for topographic order in the pattern of arborization of labeled fibers in the tectum. Terminal arbors of individual fibers covered an area of $1,500 \mu \mathrm{m}^{2}$ to $4,000 \mu \mathrm{m}^{2}$, on average, and occupied $1.5 \%$ to $3 \%$ of the tectal neuropil. From earlier studies (Stuermer, '84), we know that terminal arbors in adult goldfish are only slightly larger on average in absolute size. Because the tectal surface area increases substantially during postembryonic life, by 250 -fold, from about $0.04 \mathrm{~mm}^{2}$ on the day after hatching (present study) to about $10 \mathrm{~mm}^{2}$ in young adults (Raymond, '86; Stuermer, unpublished), the relative size of terminal arbors, expressed as a percentage of overall tectal area, is much less (by up to two orders of magnitude). Hence, the precision of the retinotectal map improves during postembryonic life, but only as a consequence of continued growth of the tectum.

\section{ACKNOWLEDGMENTS}

We gratefully acknowledge the expert technical assistance of Ms. L. Barthel and Ms. A. Habring. Dr. Stephen S. Easter, Jr. provided useful comments on an early version of the manuscript. This research was supported by NIH EY04318 (P.A.R.) and the Friedrich Miescher Foundation (C.A.O.S.)

\section{LITERATURE CITED}

Becker, D.L., and J.E. Cook (1987) Initial disorder and secondary refinement of regenerating axons in the optic tract of the goldfish: Signs of a new role for axon collateral loss. Devel. 101:323-337.

Bernhardt, R., and S.S. Easter, Jr. (1986) Map of retinal position onto the cross section of the optic pathway in goldfish. J. Comp. Neurol. 254:493510.

Easter, S.S., Jr. (1986) Rules of retinotectal mapmaking. Bioessays 5:158162.

Easter, S.S., and C.A.O. Stuermer (1984) An evaluation of the hypothesis of shifting terminals in goldfish optic tectum. J. Neurosci. 4:1053-1063.

Easter, S.S., Jr., A.C. Rusoff, and P.E. Kish (1981) The growth and organization of the optic nerve and tract in juvenile and adult goldfish. J. Neurosci. 1:793-811.

Fraser, S. (1983) Fiber optic mapping of the Xenopus visual system: Shift in the retinotectal projection during development. Dev. Biol. 95:505-511.

Fujisawa, H. (1981) Persistence of disorganized pathways and tortuous trajectories of the regenerating retinal fibers in the adult newt, Cynops pyrrhogaster. Dev. Growth Differentiation 23:215-219.

Fujisawa, H. (1987) How do retinal axons arrive at their targets? Cellular and molecular approaches. Dev. Growth Differentiation 29:105-112.

Gaze, R.M. (1970) The Formation of Nerve Connections. London: Academic Press.

Gaze, R.M., M.J. Keating, and S.H. Chung (1974) The evolution of the retinotectal map during development in Xenopus. Proc. R. Soc. Lond. (Biol.) 185:301-330.

Harris, W.A. (1980) The effects of eliminating impulse activity on the development of the retinotectal projection in salamanders. J. Comp. Neurol. 194:303-317.
Harris, W.A. (1984) Axonal pathfinding in the absence of normal pathways and impulse activity. J. Neurosci. 4:1153-1162.

Hitchcock, P., and S.S. Easter, Jr. (1988) Evidence for centripetally shifting terminals on the tectum of postmetamorphic Rana pipiens. J. Comp. Neurol. (in press)

Hollytield, J.G. (1972) Histogenesis of the retina of the killifish Funduius heteroclitus. J. Comp. Neurol. 144:373-380.

Holt, C.E., and W.A. Harris (1983) Order in the initial retinotectal map in Xenopus: A new technique for labelling growing nerve fibres. Nature. 301:150-152.

Johns, P.R. (1982) Formation of photoreceptors in larval and adult goldfish. J. Neurosci. 2:178-198.

Johns, P.R., and S.S. Easter, Jr. (1977) Growth of the aduit goldfish eye. II. Increase in retinal cell number. J. Comp. Neurol. 176:331-342.

Kajishima, T. (1960) The normal developmental stages of the goldfish, Carassius auratus. Jpn. J. Ichtyol, 8:20-28.

Meyer, R.L. (1978) Evidence from thymidine labeling for continuing growth of retina and tectum in juvenile goldfish. Exp. Neurol. 59:99-111.

Müller, H. (1952) Bau und Wachstum der Netzhart des Guppy (Lebistes reticulatus). Zool. Jb. 63:275-324.

O'Rourke, N.A., and S.E. Fraser (1986) Dynamic aspects of retinotectal map formation revealed by a vital-dye fiber-tracing technique. Dev. Biol. 114:265-276.

Rahmann, H., and G. Jeserich (1978) Quantitative morphogenetic investigations on fine structural changes in the optic tectum of the Rainbow 'Trout (Salmo gairdneri) during ontogenesis. Wilhelm Roux's Arch. Dev. Biol. 184:83-94.

Raymond, P.A. (1985) Cytodifferentiation of photoreceptors in larval goldfish: Delayed maturation of rods. J. Comp. Neurol. 236:90-105.

Raymond, P.A. (1986) Movement of retinal terminals in goldfish optic tectum predicted by analysis of neuronal proliferation. J. Neurosci. 6:24792488.

Raymond, P.A., and S.S. Easter, Jr. (1983) Postembryonic growth of the optic tectum in goldfish. I. Location of germinal cells and number of neurons produced. J. Neurosci. 3:1077-1091.

Raymond, P.A., and C.A.O. Stuermer (1987) Formation of the retinotectal projection in larval goldfish. Soc. Neurosci. Abstr. 13:1689.

Reh, T.A., and M. Constantine-Paton (1984) Retinal ganglion cell terminals change their projection sites during larval development of Rana pipiens. J. Neurosci. 4:442-457.

Sakaguchi, D.S., and R.K. Murphey (1985) Map formation in the developing Xenopus retinotectal system: An examination of ganglion cell terminal arborizations. J. Neurosci. 5:3228-3245.

Schmidt, J.T. (1985) Formation of retinotopic connections: Selective stabilization by an activity-dependent mechanism. Cell. Mol. Neurobiol. 5:6584.

Schmidt, J.T., J.C. Turcotte, M. Buzzard, and D.G. Tieman (1988) Staining of regenerated optic arbors in goldfish tectum: progressive changes in immature arbors and a comparison of mature regenerated arbors with normal arbors. J. Comp. Neurol. 269:565-591.

Sretavan, D.W., and C.J. Shatz (1986) Prenatal development of retinal ganglion cell axons: Segregation into eye-specific layers within the cat's lateral geniculate nucleus. J. Neurosci. 6:234-251.

Stuermer, C.A.O. (1984) Rules for retinotectal terminal arborizations in the goldfish optic tectum. A wholemount study. J. Comp. Neurol. 229:214232.

Stuermer, C.A.O. (1988a) The trajectories of regenerating retinal axons in the goldfish. I. A comparison of normal and regenerated axons at late regeneration stages. J. Comp. Neurol. 267:55-68.

Stuermer, C.A.O. (1988b) The trajectories of regenerating retinal axons in the goldfish tectum. II. Exploratory branches and growth cones on axons at early regeneration stages. J. Comp. Neurol. 267:69-91.

Stuermer, C.A.O. (1988c) Retinotopic organization of the developing retinotectal projection in the zebrafish embryo. J. Neurosei. 8:4513-4530.

Stuermer, C.A.O. and S.S. Easter, Jr. (1984a) A comparison of the normal and regenerated retinotectal pathways of goldfish. J. Comp. Neurol. 223:5776.

Stuermer, C.A.O., and S.S. Easter, Jr. (1984b) Rules of order in the retinotectal fascicles of goldfish. J. Neurosci. 4:1045-1051

Taylor, J.S.H., and R.M. Gaze (1985) The effects of the fibre environment on the paths taken by regenerating optic nerve fibers in Xenopus. J. Embryol. Exp. Morph. 89:383-401.

Walter, J., S. Henke-Fahle, and F. Bonhoeffer (1987a) Avoidance of posterior tectal membranes by temporal retinal axons. Development 101:909-913.

Walter, J., B. Kern-Veits, J. Huf, B. Stolze, and F. Bonhoeffer (1987b) Recog nition of position-specific properties of tectal cell membranes by retinal axons in vitro. Development 101:685-696. 